\title{
Distributed Acoustic Sensing in Volcano-Glacial Environments - Mount Meager, British Columbia
}

\section{Journal Article}

Author(s):

Klaasen, Sara; Paitz, Patrick; Lindner, Nadja; Dettmer, Jan; Fichtner, Andreas

Publication date:

2021-11

\section{Permanent link:}

https://doi.org/10.3929/ethz-b-000518921

\section{Rights / license:}

Creative Commons Attribution-NonCommercial-NoDerivatives 4.0 International

\section{Originally published in:}

Journal of Geophysical Research: Solid Earth 126(11), https://doi.org/10.1029/2021JB022358 


\section{JGR Solid Earth}

\section{RESEARCH ARTICLE \\ 10.1029/2021JB022358}

Key Points:

- We demonstrate the feasibility and potential of distributed acoustic sensing (DAS) in alpine volcanoglacial environments

- The DAS experiment at Mount Meager reveals unexpected volcanic tremor and volcanic earthquake swarms related to geothermal fluids

- Mount Meager is significantly more active than previously estimated on the basis of conventional seismic instruments in the area

Supporting Information:

Supporting Information may be found in the online version of this article.

Correspondence to:

S. Klaasen,

sara.klaasen@erdw.ethz.ch

Citation:

Klaasen, S., Paitz, P., Lindner, N., Dettmer, J., \& Fichtner, A. (2021). Distributed acoustic sensing in volcano-glacial environments-Mount Meager, British Columbia. Journal of Geophysical Research: Solid Earth, 126, e2021JB022358. https://doi. org/10.1029/2021JB022358

Received 4 MAY 2021

Accepted 2 NOV 2021

\section{Distributed Acoustic Sensing in Volcano-Glacial Environments-Mount Meager, British Columbia}

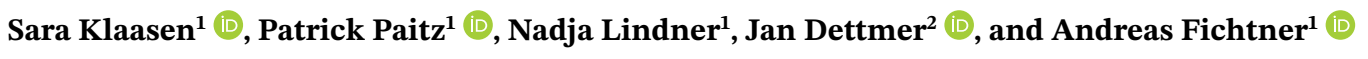 \\ ${ }^{1}$ ETH Zürich, Zürich, Switzerland, ${ }^{2}$ University of Calgary, Calgary, AB, Canada
}

\begin{abstract}
We demonstrate the logistic feasibility and scientific potential of distributed acoustic sensing (DAS) in alpine volcano-glacial environments that are subject to a broad range of natural hazards. Our work considers the Mount Meager massif, an active volcanic complex in British Columbia, estimated to have the largest geothermal potential in Canada, and home of Canada's largest recorded landslide in 2010. From September to October 2019, we acquired continuous strain data, using a 3-km long fiberoptic cable, deployed on a ridge of Mount Meager and on the uppermost part of a glacier above 2,000 $\mathrm{m}$ altitude. The data analysis detected a broad range of unexpectedly intense, low-magnitude, local seismicity. The most prominent events include long-lasting, intermediate-frequency $(0.01-1 \mathrm{~Hz})$ tremor, and high-frequency $(5-45 \mathrm{~Hz}$ ) earthquakes that form distinct spatial clusters and often repeat with nearly identical waveforms. We conservatively estimate that the number of detectable high-frequency events varied between several tens and nearly 400 per day. We also develop a beamforming algorithm that uses the signal-to-noise ratio (SNR) of individual channels, and implicitly takes the direction-dependent sensitivity of DAS into account. Both the tremor and the high-frequency earthquakes are most likely related to fluid movement within Mount Meager's geothermal reservoir. Our work illustrates that DAS carries the potential to reveal previously undiscovered seismicity in challenging environments, where comparably dense arrays of conventional seismometers are difficult to install. We hope that the logistics and deployment details provided here may serve as a starting point for future DAS experiments.
\end{abstract}

Plain Language Summary Distributed acoustic sensing (DAS) is an emerging technology to measure microscopic ground motion by sending laser pulses through fiber-optic cables, which are commonly used for telecommunication. A cable of several kilometers length provides thousands of measurement points, which can yield highly detailed information about the propagation of seismic waves excited by earthquakes. The ease of deploying a fiber-optic cable, compared to the challenge of installing thousands of conventional seismometers, opens new opportunities for earthquake studies in remote and hazardous areas. Here, we present the first application of DAS in a volcano-glacial environment. Mount Meager, the site of the experiment in British Columbia, is an active volcano known for its geothermal potential and for hosting the largest landslide in recorded Canadian history. Using a 3-km-long cable deployed on Mount Meager's ridge and glacier, we were able to detect an unexpectedly broad range of seismic signals, including up to 400 small earthquakes per day and volcanic tremor that may last for many hours. The most likely origin of these events is the movement of fluids within the geothermal reservoir, and their existence indicates that Mount Meager is substantially more active than previously thought.

\section{Introduction}

Mount Meager is an active volcano in the Garibaldi Volcanic Belt in British Columbia, Canada, characterized by a high geothermal potential and a broad range of natural hazards. It is located $60 \mathrm{~km}$ northwest from the nearest town of Pemberton, with a population of approximately 2,500, and $150 \mathrm{~km}$ north of Vancouver (Figure 1). The volcano was home to the largest recorded landslide in Canada in 2010 (Roberti, Ward, de Vries, van Wyk, Friele, et al., 2018) but also offers high geothermal potential (Jessop et al., 1991). This fascinating environment may be further destabilized by melting glaciers, related to climate change in the region (Roberti, Ward, de Vries, van Wyk, Falorni, et al., 2018). The volcano poses significant risks to the population in the adjacent Lillooet Valley, and geothermal development requires careful hazard assessment. This provides numerous motivations to increase our understanding of Mount Meager and expand monitoring. 


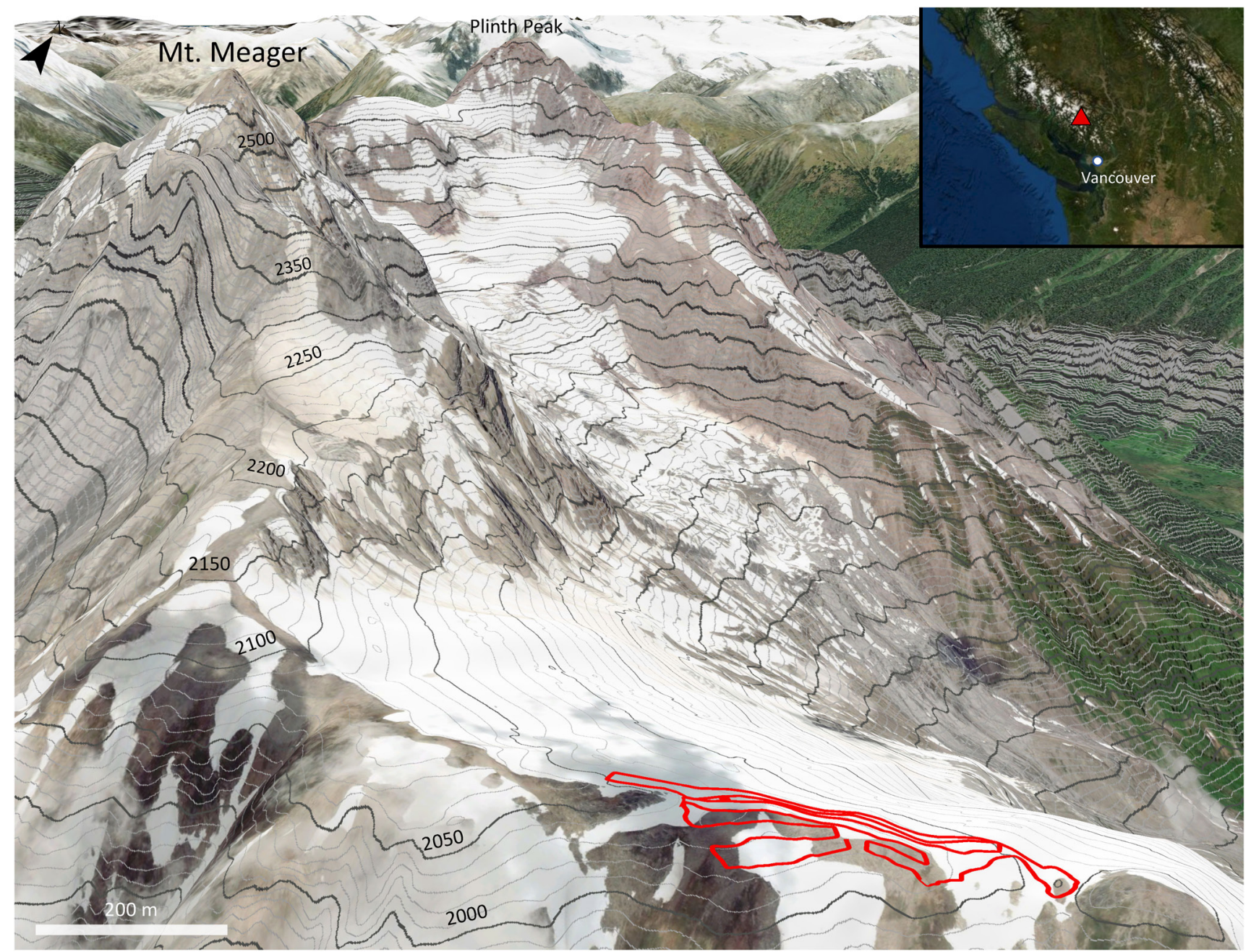

Figure 1. Geographic location and map overview. Mount Meager is located around $150 \mathrm{~km}$ north of Vancouver, British Columbia, Canada, in the Garibaldi Volcanic Belt. We deployed the fiber-optic cable, shown in red, on one of its ridges and its north-facing glacier slightly above 2,000 m altitude. Figure 2 shows the cable in more detail. (Sources: topography Esri, 2009, inset [Google Maps]).

Mount Meager is a calc-alkaline composite stratovolcano with a peak elevation of 2,645 m (Michol et al., 2008). It is part of a volcanic complex of the Pliocene to Holocene age that partly covers granitic and metamorphic basement rocks of the Mesozoic age. The basement complex is composed of quartz diorite and other less common metamorphic rocks from the Mesozoic age (Read, 1990). The bulk of the overlying volcanic complex has been formed during the three main periods of volcanic activity (Read, 1990). The first period between $1.9 \pm 0.2 \mathrm{Ma}$ and $1.0 \pm 0.1 \mathrm{Ma}$ of rhyodacite tephra on the edge of the southwestern part of the complex was followed by a period of andesitic volcanism between $1.0 \pm 0.1$ and $0.5 \pm 0.1$ in the southern and central parts of the complex (Read, 1990). The third and most recent period of rhyodacite volcanism between $0.1 \pm 0.02 \mathrm{Ma}$ and 2360 B.P. created rhyodacite flows, tephra, and lava domes that resulted in the Pebble Creek Formation in the northeast of Mount Meager (Read, 1990). The eruption produced both welded and non-welded rhyodacitic block and ash flow deposits containing phenocrysts of plagioclase, orthopyroxene, amphibole, biotite, and other minor oxides (Hickson et al., 1999; Michol et al., 2008). The eruption was episodic and began with a Plinian phase that produced pumice fall deposits and ignimbrites (Hickson et al., 1999), which was followed by a less explosive phase that produced block and ash flow deposits in the Lillooet River valley.

Volcanoes pose constant threats to nearby populations, and their seismic monitoring aids in anticipating eruptive events, since volcanic activity is generally accompanied by a spectrum of seismic signals (McNutt 
\& Roman, 2015). These can be related to a range of source mechanisms, caused by mechanical stresses in the solid crust, magma movement, or geothermal fluids (Chouet, 1996). Seismic signals tell the story of the underlying physical processes that govern the eruptive behavior of volcanoes and their geothermal systems. However, volcanoes tend to be in harsh terrains and isolated from most infrastructure which makes measuring their signals challenging.

Distributed acoustic sensing (DAS) is an emerging seismic measurement technology with the potential to acquire large, densely sampled, data volumes with lower labor and financial costs compared to conventional arrays of similar sizes, which is especially useful in remote environments (Walter et al., 2020). DAS utilizes a fiber-optic cable and an interrogation unit that sends light pulses through the cable. Naturally occurring inhomogeneities in the cable cause back-scattering of the light, which is measured by the interrogation unit. Any shortening or elongation of the cable causes a phase shift in the back-scattered light, and this phase shift is proportional to axial strain along the cable. The result is a dense network of strain measurements that are sampled every few meters along a cable, which can extend up to several kilometers with a sampling rate in the $\mathrm{kHz}$ range (Hartog, 2017). The broadband response of DAS can aid to recover a wide range of signals in various applications (Jousset et al., 2018; Lindsey et al., 2020; Paitz et al., 2020). DAS has initially been used for vertical seismic profiling in hydrocarbon and geothermal exploration (Mateeva et al., 2014) and has subsequently been adapted to a wider range of seismological applications (Henninges et al., 2021; Lindsey et al., 2017; Martin et al., 2017; Walter et al., 2020; Zhan, 2020).

With this contribution, we aim to explore the use of DAS in remote volcano-glacial environments where challenging terrain and the abundance of natural hazards render the deployment of large conventional seismometer arrays nearly impossible. This may carry the potential to significantly advance the field of active volcano monitoring and imaging, with measurements of both high spatial and temporal resolutions.

Previous uses of DAS in volcanic environments have compared the strain recordings with a dense seismometer array at Etna volcano (Currenti et al., 2021), and an extensive experiment in Iceland used DAS to image seismological and structural features (Jousset et al., 2018). Applications of DAS in glacial settings have greatly improved the detectability and location accuracy of stick-slip icequakes (Walter et al., 2020). At Mount Meager, a wide range of environmental signals can be expected, including long-term deformation related to slope instability, as well as seismic waves from volcanic activity, rockfalls, icequakes, and landslide precursors. In this study, we initially focus on the detection and characterization of seismic signals. Furthermore, this research also reflects the plain curiosity to discover what we could possibly learn from DAS arrays deployed directly on a volcano.

This manuscript is organized as follows: First, in Section 2, we explain the setup of the experiment and the necessary logistics. The initial data exploration in Section 3 provides a rough summary of the wealth of signals contained in the recordings, and is followed by a more thorough investigation of specific event types in different frequency ranges in Section 4. Finally, we discuss the potentials and pitfalls of this analysis with DAS in volcano-glacial environments in Section 5.

\section{Experimental Setup and Logistics}

We acquired seismological data by deploying a fiber-optic cable and the DAS interrogator unit (IU) OptaSense ODH3 along a ridge of Mount Meager that we considered sufficiently stable. In addition to the DAS equipment, we installed six geophones, Inova Hawk with 10-Hz design frequency, and a broadband seismometer, 20-s Nanometrix Trillium with a response flat to velocity from $20 \mathrm{~s}$ to $100 \mathrm{~Hz}$, mostly for the purpose of data comparison. The IU measures strain data, while the geophones and broadband seismometer record velocity. This exceptionally harsh and hazardous environment posed significant challenges related to power supply, transport, IU setup, and cable coupling.

One of the main difficulties was the construction of a reliable power source that was quiet, operated autonomously for more than one month, and did not exceed a maximum weight of around $700 \mathrm{~kg}$ that could be transported as a sling load by the available helicopter under good weather conditions, which are rare in the Coast Mountains at altitudes above 2,000 m. We managed to transport the power source using a modular system with a separate fuel tank and battery pack that we distributed over multiple sling loads. 


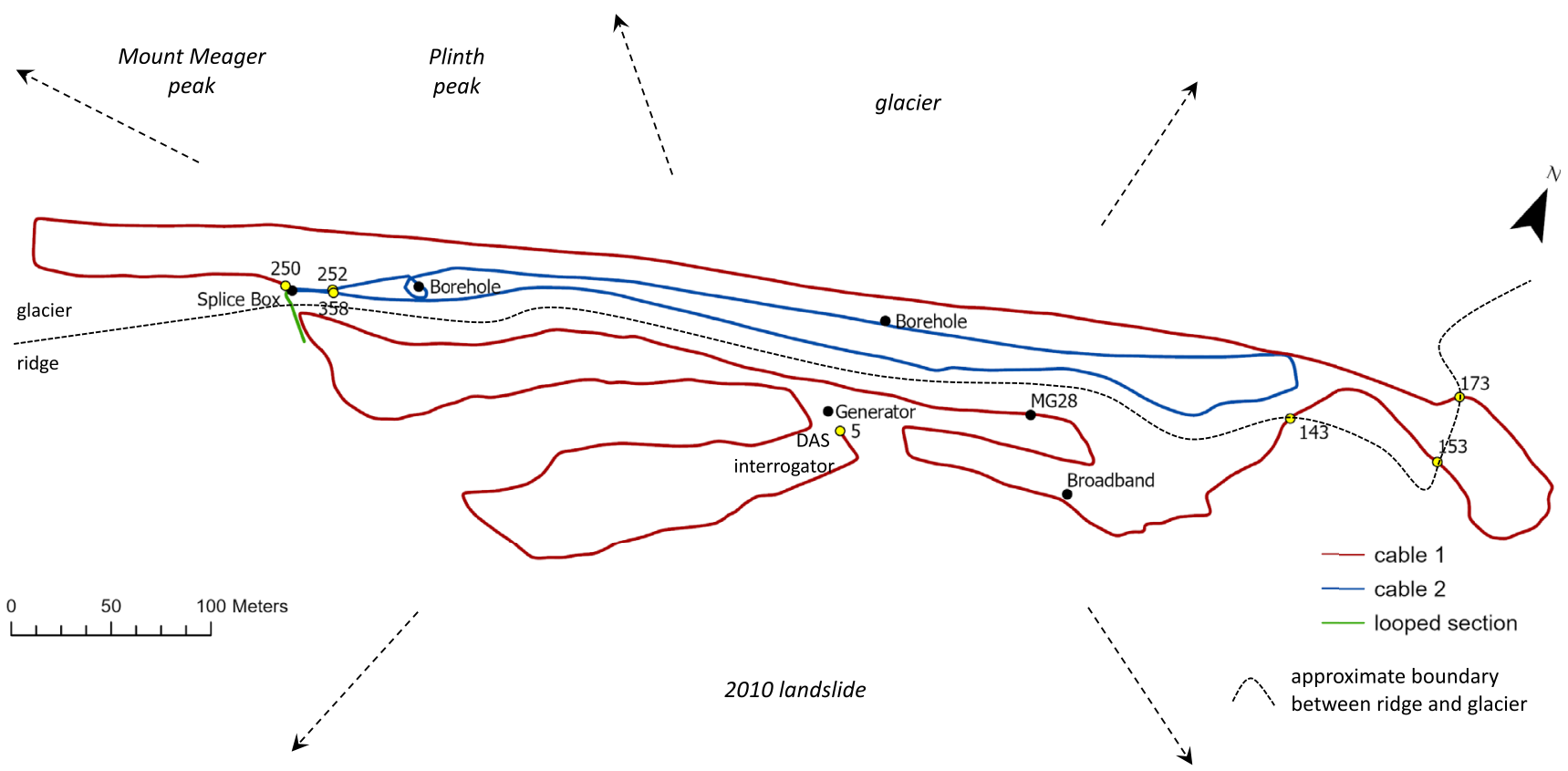

Figure 2. Detailed layout of the fiber installation, indicated in Figure 1. We used two different cables, spliced together at the splice box. The looped section represents the trench where cable 2 loops back and forth four times. Two boreholes with a depth of $5 \mathrm{~m}$ each are included, as well as the location of the generator, the co-located geophone (MG28), and broadband seismometer (Broadband). The numbers represent the relative locations of a few channels to show the orientation of the cable and the position of subsurface changes from ridge to firn. The position of the DAS interrogator corresponds to channel number 5 . Dashed arrows and italic labels indicate the approximation location of major geologic/topographic features. More technical details of the cable are summarized in Supporting Information S1 and S2.

To ensure autonomy of the system during the experiment, the power source consisted of a $5.5 \mathrm{~kW}$ generator that charged a $550 \mathrm{Ah}$ battery bank. The gasoline-powered generator had auto-start functionality and was mounted on adjustable airbags to minimize vibration and operating noise. With a separate fuel tank of $434 \mathrm{~L}$ volume, we ensured the availability of sufficient backup power. We placed the generator in an especially designed insulated double-room enclosure, where the first room contained eight $275 \mathrm{~A} / \mathrm{hr}, 6 \mathrm{~V}$ Absorbent Glass Matt (AGM) batteries. The second room had a 4 kW Inverter with 105 A charging capacity, an $\mathrm{AC}$ load center, and the generator start controls with remote functions. The power source worked reliably throughout the experiment, and we noted only minor gaps in the data due to short power outages.

Several helicopter flights were necessary to deploy the equipment, including four cables, generators, batteries, the IU, and people to install them. The installation was completed by five people during 3 days, and an additional two people for 2 days to set up the complete experiment. Most of the physical labor was related to the deployment of the cable, which had a weight of around $50 \mathrm{~kg} / \mathrm{km}$, that was carried by two people. The cable contained four single-mode fibers, and we placed it in a small trench of around $10 \mathrm{~cm}$ depth along the ridge, where digging was a limiting and physically intense factor. On the glacier, we produced a trench with a depth of roughly $40 \mathrm{~cm}$ using a standard chainsaw. The last $120 \mathrm{~m}$ of the cable were looped back and forth four times within a single trench of roughly $30 \mathrm{~m}$ length. Four people managed to do the splicing, the installation of the generator, the satellite modem, the six geophones on the ridge, and the hammer tap tests in 1 day.

Figures 1 and 2 show the cable geometry along the ridge. The irregular geometry is the result of a compromise between the maximization of geographic data coverage, accessibility, terrain/slope stability, and the possibility to produce a trench of at least a few $\mathrm{cm}$ depth without excessive physical effort.

The retrieval of the equipment required four sling loads and three helicopter trips for people and batteries. It took four people 2 days to recover the equipment. However, the site had been covered in so much snow that the retrieval of the cable and some of the geophones was delayed until the following summer. 


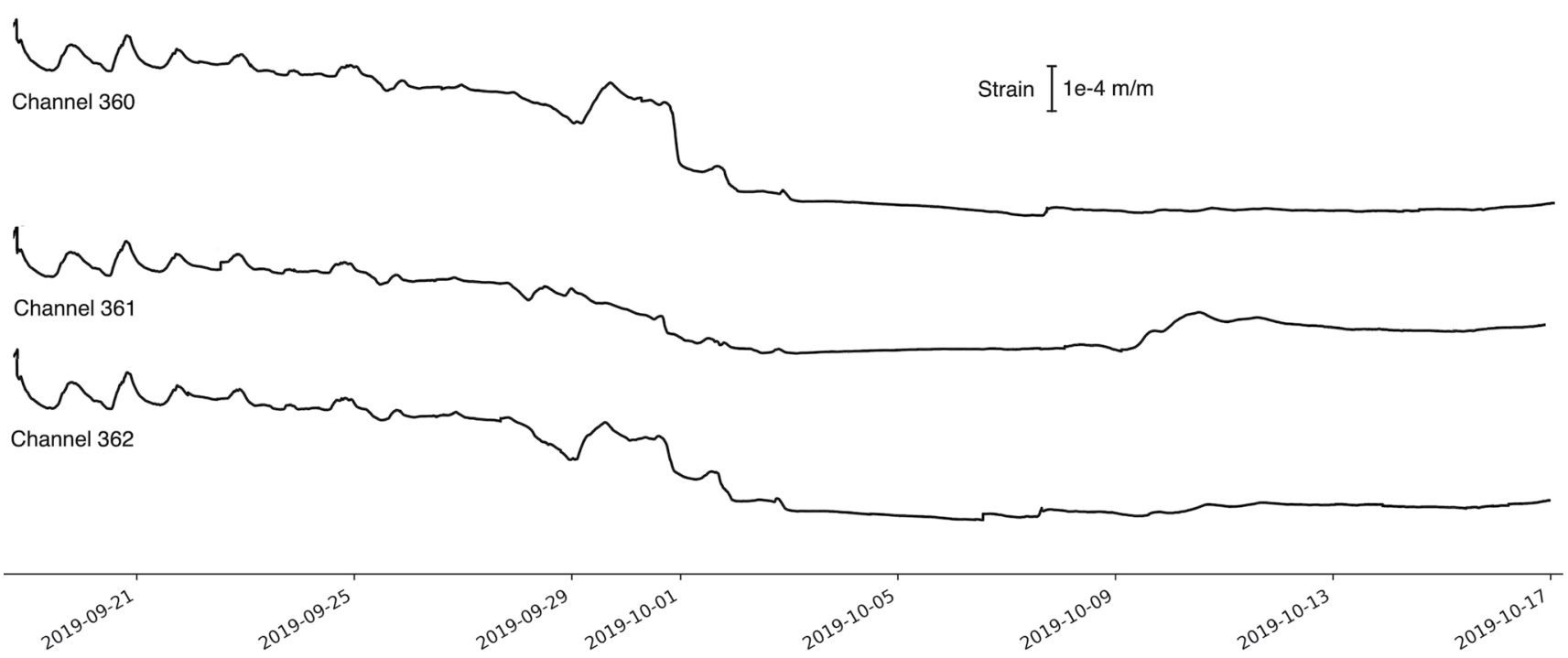

Figure 3. DAS-based strain recordings for the acquisition period at three neighboring channels within the looped section of the cable layout. To eliminate higher-frequency oscillations, each plotted time sample represents a $1 \mathrm{~s}$ average (corresponding to an average of over 1,000 samples of the raw data). The traces are nearly identical for approximately the first 10 days of the experiment but then lose coherence. This is most likely due to localized changes in coupling or soil properties, possible related to freezing, as temperatures gradually decreased.

Other considerations included local wildlife, as all equipment had to be protected from rodents and bears. The steam drill performed poorly in firn, with boreholes limited to $\sim 5 \mathrm{~m}$, while the objective was $15 \mathrm{~m}$. The amount of fiber in the boreholes was too limited to produce any distinguishable waveforms. Furthermore, bad weather during the deployment and thick snow cover during the recovery limited the number of hammer tap tests, and the attenuation of the hammer signal appeared to be very large at those wavelengths. Therefore, the geographic location of DAS channels is based on the interpolation of GPS waypoint measurements and not on tap tests. The uncertainty of the GPS measurements is 1-2 m, and the channel locations should be accurate within a few meters.

We succeeded to install $3 \mathrm{~km}$ of cable with 375 channels at a spacing of $8 \mathrm{~m}$ and a gauge length of $7 \mathrm{~m}$. Continuous measurements were acquired between September 18, 2019 20:34:00 and October 17, 2019 01:20:00 UTC at a sampling rate of $1 \mathrm{kHz}$, which resulted in $1.5 \mathrm{~TB}$ of strain data in the HDF5 format. A movie summarizing the deployment and recovery can be found on the YouTube Channel of the Seismology \& Wave Physics Group at ETH Zurich (last accessed: April 23, 2021).

\section{Initial Data Exploration}

At frequencies below $0.01 \mathrm{~Hz}$, the data are characterized by strain variations on the order of $1 \times 10^{-4} \mathrm{~m} / \mathrm{m}$ on an approximately daily time scale. A representative example of three neighboring channels from the looped section of the DAS array is shown in Figure 3. During the first 10 days of the experiment, strain observed on these channels is nearly identical, cyclic with a $\sim 24$-hr period, and most likely caused by diurnal thermal expansion and contraction. The cyclicity disappears on September 26, when accumulating snow insulated the cable from temperature variations. Meteorological measurements, including temperature and precipitation, from the closest station in Meager valley, are summarized in Supporting Information S1 and S2. Finally, with further decreasing temperatures, the traces largely lose coherence around September 29 , possibly as a consequence of freezing and related small-scale changes in cable-ground coupling.

The recordings from the first 10 days, exemplified in Figure 3, suggest that DAS has the potential to measure long-term variations in strain, related, for instance, to slope instability, which would be desirable to capture on Mount Meager. However, at the current stage, the effects of changes in coupling do not seem to be sufficiently understood to warrant such an analysis here. Therefore, in what follows, we focus on signals at frequencies above $0.01 \mathrm{~Hz}$, which we process with standard tapering and bandpass filtering, implemented with ObsPy (Beyreuther et al., 2010; Krischer et al., 2015). 
Intermediate Frequency Band $(0.01-1 \mathrm{~Hz})$

10:06:00 10:09:00 10:12:00 10:15:00

High Frequency Band (1 - $45 \mathrm{~Hz})$

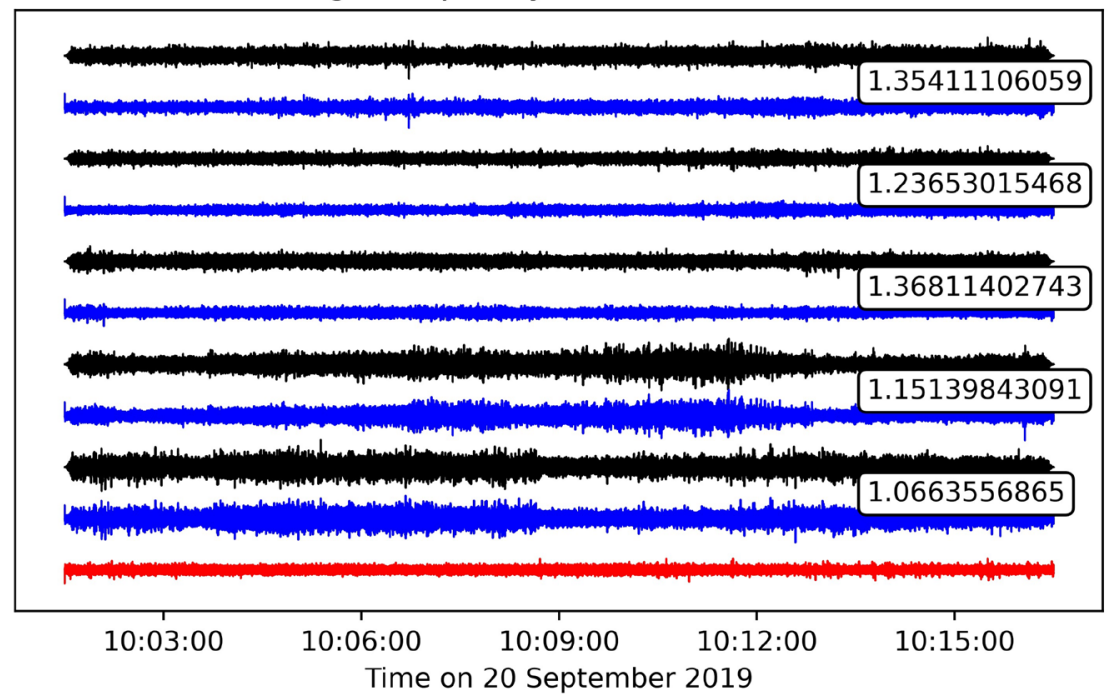

Figure 4. DAS recordings at frequencies between $0.01-1 \mathrm{~Hz}$ (top) and $1-45 \mathrm{~Hz}$ (bottom) within the looped section of the cable. Shown in black are the data from the individual channels. The red trace at the bottom of the subfigures is the stack of individual channels. Blue traces are the difference between the stack and the individual recordings. The numbers on the right show the RMS of each channel divided by the RMS of the difference between that channel and the stack. Values around 1 indicate the dominance of incoherent signals, whereas values around 4 suggest that only roughly $25 \%$ of the total signal is incoherent.

Within the intermediate-frequency band of 0.01-1 Hz, different channels show remarkably similar signals, as illustrated in Figure 4a. The coherency is visible along the entire cable, but is particularly pronounced in the channels of the looped section (marked green in Figure 2). This suggests that these signals are predominantly of natural origins, such as ambient vibrations, and not due to incoherent instrument (optical) noise. This property allows us to stack the channels in the looped section without the prior application of any time shifts. Plotting a longer duration of the intermediate-frequency stack reveals distinct changes in the amplitudes of the data, which we further discuss in Section 4.1.

As shown in Figure 4b, the coherency between neighboring channels mostly disappears when we consider frequencies above $5 \mathrm{~Hz}$, even though the wavelength is still 1-2 orders of magnitude larger than the channel 
spacing. While this indicates that incoherent noise plays a more significant role, the arrivals of transient waves are clearly visible within the high-frequency band of 5-45 Hz. These are the focus of Section 4.2.

\section{Event Identification and Characterization}

The initial exploration of the data has shown two distinct types of signals that can be interpreted with reasonable confidence. Intermediate-frequency $(0.01-1 \mathrm{~Hz})$ events are characterized by their long duration and seem to appear on all traces simultaneously, while high-frequency $(5-45 \mathrm{~Hz})$ events are transient and arrive at different times at different channels.

\subsection{Intermediate-Frequency Events}

Within the intermediate frequency range, the maximum amplitudes of the signals can change significantly over time, and stay at a comparatively high level for up to several hours. This is most clearly visible in the stack of traces within the looped section, shown in Figure 5 for the period from September 19 to October 2 , 2019. These long-duration events are most prominent between around $0.01-0.2 \mathrm{~Hz}$, and their amplitude changes can be either abrupt (within minutes) or smooth (over several hours).

The events are not correlated with the local weather, including wind, rain, and temperature, as retrieved from a station in the adjacent valley (Consortium Pacific Climate Impacts, 2013), and summarized in Supporting Information S1 and S2. Though the weather on the ridge and in the valley may differ significantly, the fact that increasing snow cover of more than $1 \mathrm{~m}$ affected neither the occurrence nor the amplitude of these events, makes a meteorological origin rather unlikely. A seismic origin is further supported by the long-range coherence of the signals, which would not be expected from wind noise. The abrupt changes in the nature of these events suggest that they are not related to microseismic ocean noise.

The long-duration events seem to occur simultaneously and coherently at all traces. Since their wavelengths are around an order of magnitude larger than the aperture of the DAS array, we were not able to meaningfully constrain the back azimuth or slowness of the events with beamforming. The more widely spaced geophone array was not sensitive to signals below $1 \mathrm{~Hz}$ and could therefore not aid in the event characterization. The broadband seismometer, co-located with the cable, largely confirms the presence of these events. However, details differ, most likely due to the different coupling and directional sensitivities of the instruments.

Based on the previous line of arguments, we hypothesize that the long-duration, intermediate-frequency signals are volcanic tremor. In the absence of any observable magmatic activity, they are most likely related to fluid movement within the geothermal reservoir. However, this tremor is hard to fit within the established categories of documented volcanic signals, as it constitutes a continuous and very-low-frequency observation at a calc-alkaline stratovolcano. Figure 6 shows an example of a typical tremor recorded with the DAS array on Mount Meager. It does not contain any overtones or high-frequency onsets, yet it seems to steadily increase all present frequencies.

Tremor at volcanoes with high-viscosity lava can show spectral peaks at higher frequencies, as well as several overtones (Schlindwein et al., 1995), suggesting a resonating medium. Volcanic tremor at basaltic volcanoes or volcanoes with a large amount of volatiles may feature a cyclic appearance in a narrow-band spectrum (around 1-5 Hz), which may indicate the involvement of fluids in the tremor generation (Wassermann, 2012). Transient ultra low-frequency (ULF, $<0.01 \mathrm{~Hz}$ ) and very low-frequency (VLF, 0.01-0.1 Hz) events have been observed at Stromboli and Aso volcanoes (De Martino et al., 2005; Kawakatsu et al., 2000), and Kawakatsu et al. (2000) related these signals to interactions with an aquifer. However, ULF and VLF events have not yet been recorded at most andesitic and rhyolitic volcanoes (Wassermann, 2012), and the latest period of volcanic activity at Mount Meager was characterized by rhyodacite volcanism. Still, Mount Meager has a large geothermal reservoir, and tremor can be linked to the hydrothermal boiling of groundwater (Konstantinou \& Schlindwein, 2003). Importantly, the characteristics of tremor can be unique to each volcano, and no previous record of tremor at Mount Meager exists. 


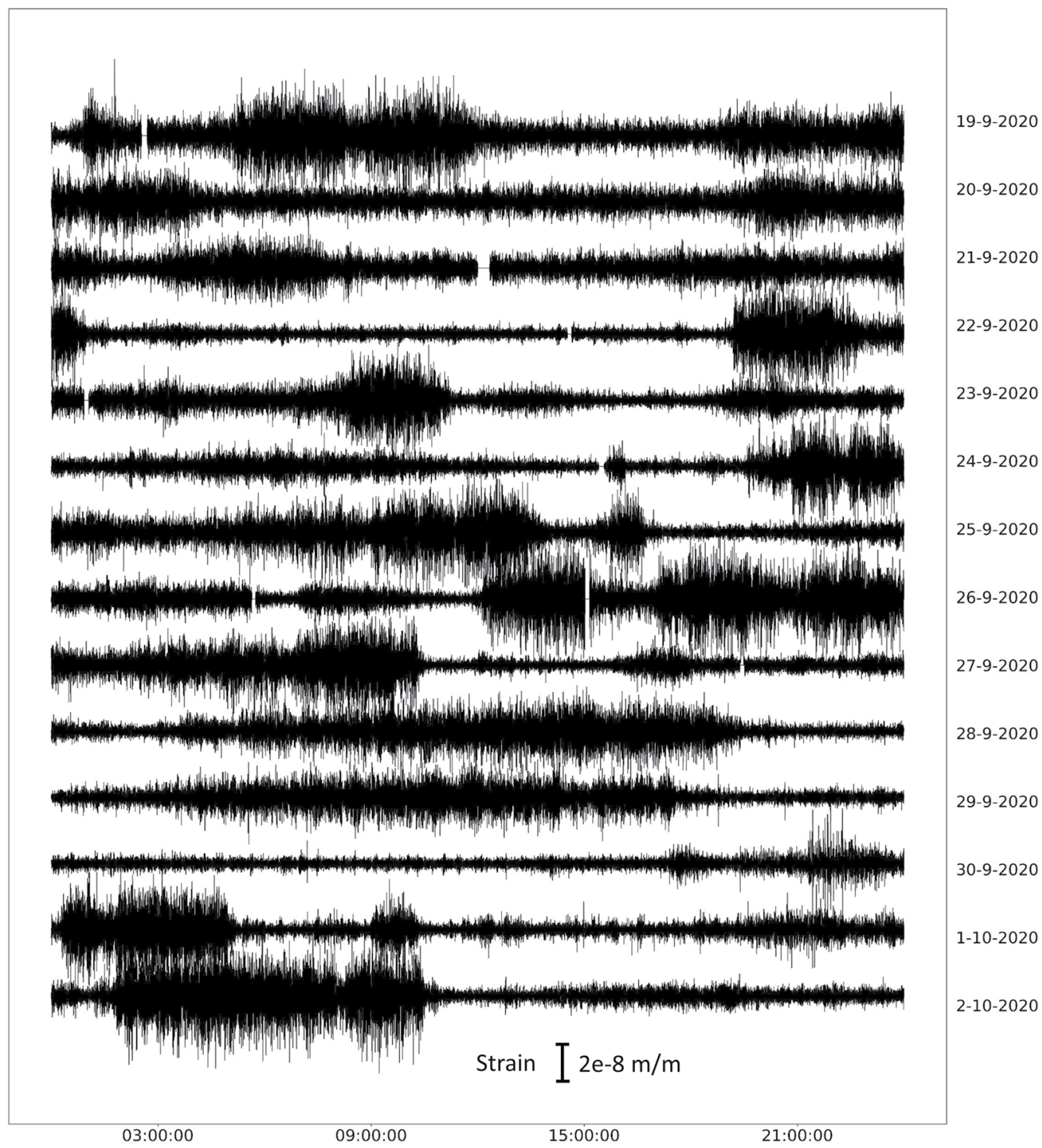

Figure 5. Linear stack of the channels in the looped part of the cable, previously described in Section 3 , between September 19 and October 2, 2019. The frequency range is $0.01-1 \mathrm{~Hz}$. The changes in the signal amplitude become particularly obvious when plotted over longer time periods, and they are also present on the other channels along the entire cable. Gaps in the signal are due to data gaps or very noisy periods where all channels contain large artifacts.

\subsection{High-Frequency Events}

Transient events with a frequency content roughly between 5 and $45 \mathrm{~Hz}$, exhibit a clear moveout, arriving at different parts of the cable at different times. The character of these events differs strongly in the various sections of the cable, as shown in the examples of Figure 7. We see significantly longer coda on the ridge, suggesting more intense scattering and less attenuation, compared to the fiber section on the glacier, where coda waves are practically absent. As expected, the signals arrive nearly simultaneously at the channels in the looped section of the cable.

\subsubsection{Event Detection and Statistics}

Owing to a large number of high-frequency events, we employed a conventional Short-Term Average/ Long-Term Average (STA/LTA) algorithm (Withers et al., 1998) for their identification. Though more elaborate event detection algorithms may be available, the STA/LTA algorithm provides a reproducible method that identifies events based on their amplitudes compared to the background noise. This approach has the 
a) Time-domain strain

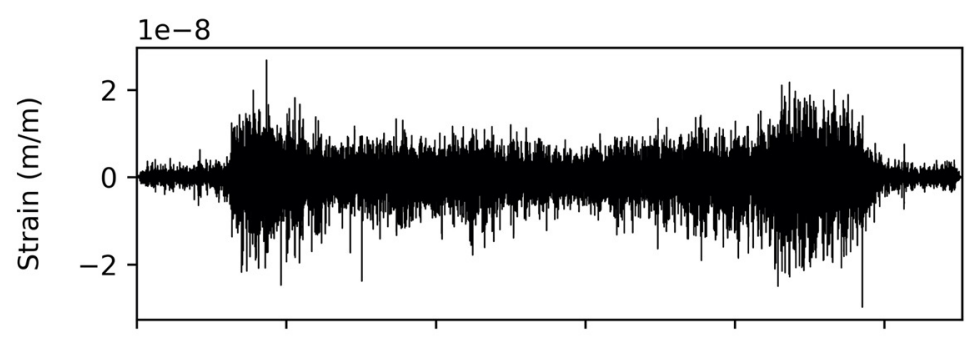

b) Power-spectral density

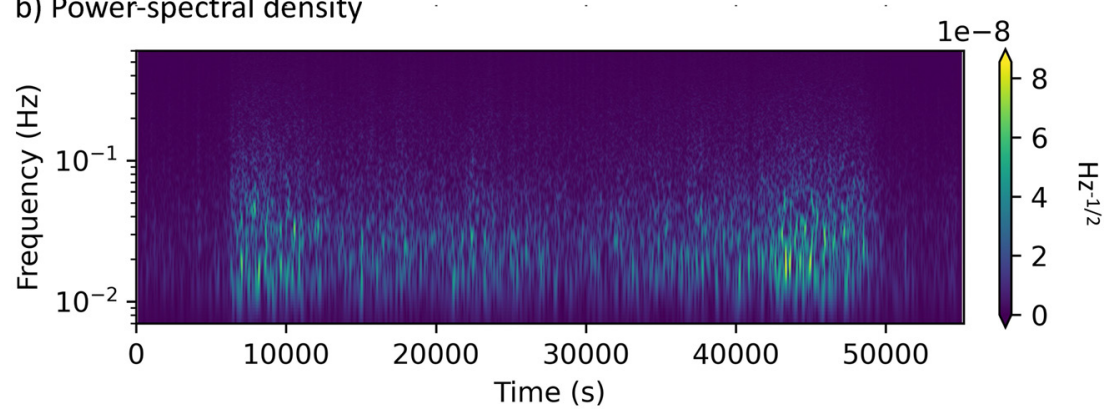

Figure 6. Representative example of an individual low-frequency event from the stacked section. The time axis begins at 5 p.m. on October 10 and ends at 8 a.m. on October 11, 2019. The time series in the $0.01-1 \mathrm{~Hz}$ frequency range is shown in the top panel, and the time-frequency representation is shown below. At the onset of the event, the amplitude increases abruptly for all present frequencies. In contrast, the termination of the event is more gradual.

additional benefits of selecting events that are suitable for subsequent beamforming analysis and for providing a conservative estimate of the number of events that exist unambiguously. We applied the detection algorithm to the stack of channels in the looped section, with a zero-phase Butterworth bandpass filter between 5 and $45 \mathrm{~Hz}$ that helps to prevent artifacts from causing false triggers. The STA window length was $0.3 \mathrm{~s}$, the LTA window length $60 \mathrm{~s}$, the trigger value 7.5, and the detrigger value 1.5. We determined these values by trial and error on a shorter time series, so as to detect events in a conservative fashion. We later manually excluded false triggers due to gaps in the data.

In total, the STA/LTA algorithm detected around 3,000 distinct high-frequency events within the 30 days of the experiment, that is, on average 100 events per day. The majority of these events are equally visible in the data from the nearby geophone and the broadband seismometer, to which we also applied the STA/ LTA detector. As illustrated in Figure 8a, the temporal distribution of events shows very similar trends on all three instruments, though the stacked DAS channels consistently yield a larger number of detectable events. This is most likely a consequence of a higher signal-to-noise ratio (SNR) in the stacked DAS recordings, compared to the single channels of the geophone and broadband seismometer.

Figure 8 reveals two distinct periods of increased activity, roughly lasting from September 28 to October 1 and from October 7 to 11, 2019. The comparatively large number of detections may represent an actual increase in seismicity, but is also likely to have a meteorological component. In fact, the precipitation peaks around October 26 and October 7, shown in Supporting Information S1 and S2, produced a snow cover that provided additional insulation, thereby lowering the noise level. Cold temperatures, especially from October 8 to 11, must have led to more profound freezing, likely causing a decrease in visco-elastic attenuation.

These high-frequency events could have many different origins, including natural processes or man-made events, such as explosions in a nearby quarry. Recognizing that natural processes are often characterized by power-law behavior (Corral \& Gonzalez, 2019), we estimate the distribution of signal power in the events as a function of their frequency of occurrence for the fiber-optic cable, the broadband seismometer, and the geophone. In the interest of simplicity, we define signal power as 

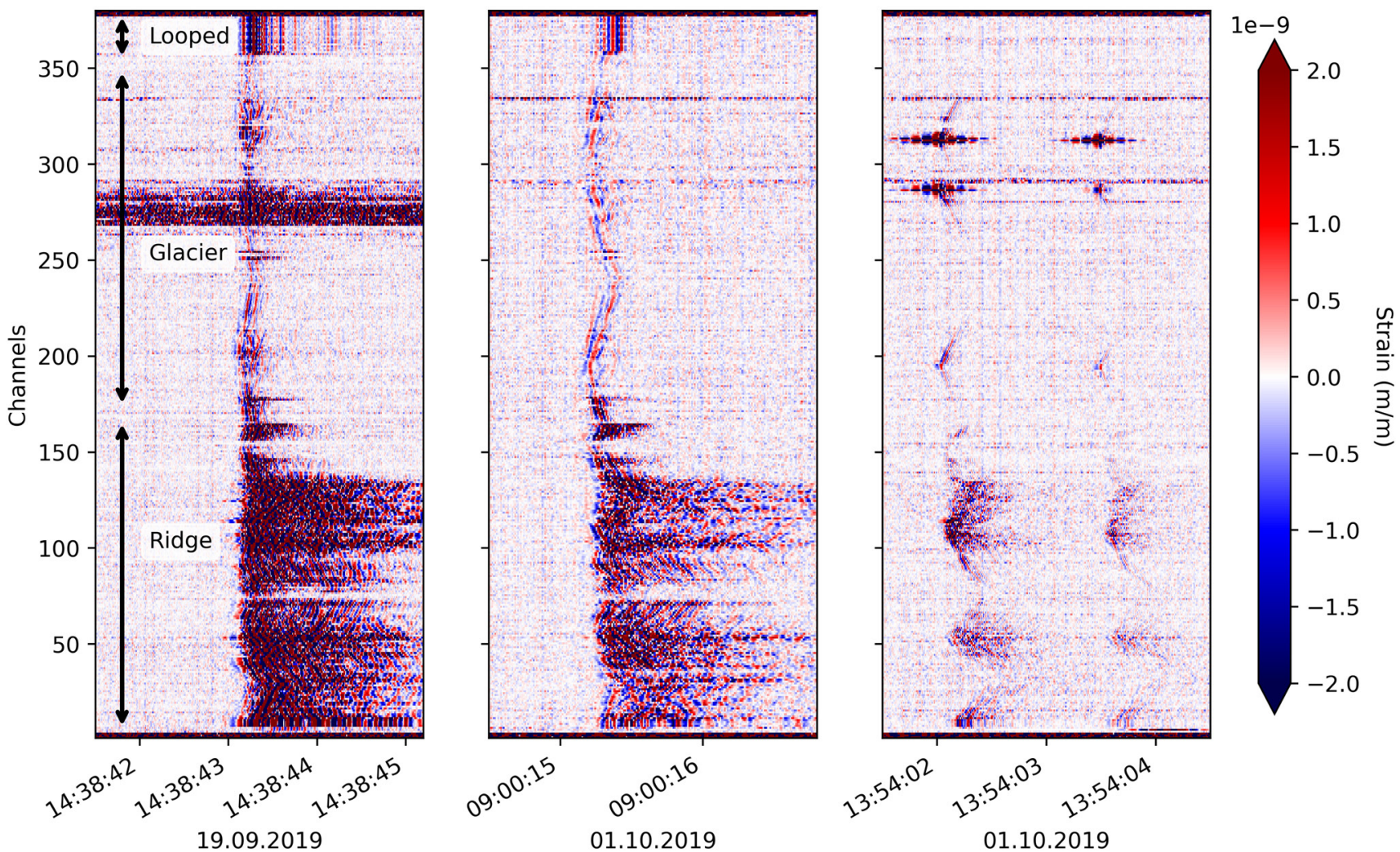

Figure 7. Four examples of high-frequency events, as visible in the different seismic sections of the DAS array (The rightmost panel contains two events). The strain values are clipped to enhance visibility, especially of the coda waves. The different sections of the array, on the ridge, on the glacier, and in the loop, reveal distinctly different characteristics, most likely due to local differences in scattering and attenuation.

$$
P=\frac{1}{n} \sum_{i=0}^{n} y_{i}^{2} .
$$

Here, $P$ is the power, $n$ is the total number of data points in the time series, and $y_{i}$ is the amplitude of the $i$ th sample. The length of the time series equals the duration of the event signal that is above the noise level. The resulting frequency-power plots, shown in Figure 8b, reveal an approximately exponential behavior in a range extending from the maximum detected power to a lower power that is close to the noise-dependent detection limit of the STA/LTA algorithm. This behavior hints at a natural origin of the events rather than an anthropogenic one. Anthropogenic events often tend to repeat with similar energies, resulting in a flat curve. We note that the physical units of the DAS recordings (strain), and the broadband seismometer and geophone recordings (velocity) are different. The DAS recordings have not been converted to $\mathrm{m} / \mathrm{s}$, as this conversion would not be robust enough, given the layout of our experiment, and none of our analyses requires such a conversion.

We compared the timing of the high-frequency events to known catalogs of regional earthquakes within British Columbia and Canada, as well as to teleseismic events and known mine blasts, however, without a clear correlation. From this, we infer that the detected events are of very local nature.

The straight lines in Figure 8b represent least-squares fits to the frequency-power distributions within their respective linear (exponential) range. In a slight abuse of terms, we may refer to the slope of the lines as a $b$-value, which would be comparable to the $b$-value of a Gutenberg-Richter distribution (Gutenberg, 1956) if the epicentral distances were all similar. Estimated $b$-values above one indicate a larger proportion of seismicity with smaller magnitudes, which tends to be observed in regions with volcanic earthquakes and earthquake swarms (Roberts et al., 2015). While a strict quantitative comparison between the $b$-values in 

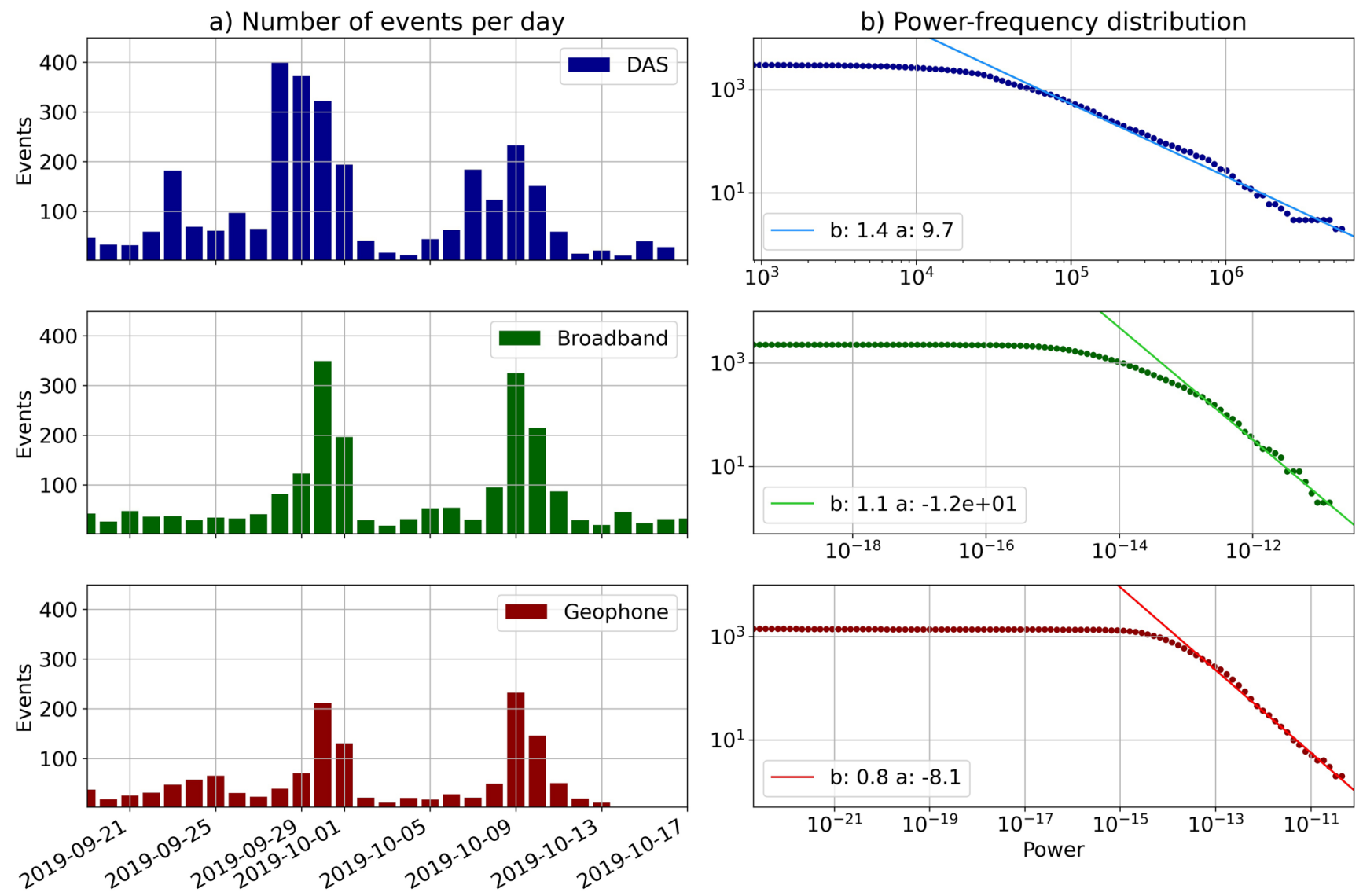

Figure 8. High-frequency event statistics. (a) The number of detected events per day during the acquisition period from the DAS array (blue), the broadband seismometer (green), and the geophone (red). The geophone only recorded until 13 October 2019. (b) Frequency-power distribution of the high-frequency events detected on the DAS array, the broadband seismometer, and the geophone. Straight lines represent least-squares fits within the power range where the distribution is approximately exponential (linear in logarithmic scale).

Figure $8 \mathrm{~b}$ and the Gutenberg-Richter $b$-values is not easily possible, the estimated numbers do suggest a natural origin with a frequency-size distribution well within the commonly observed range.

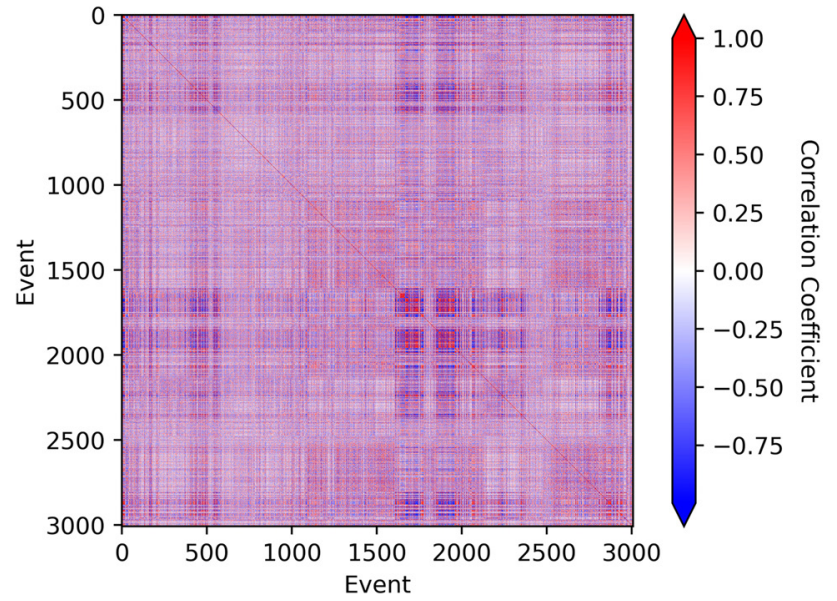

Figure 9. The matrix of maximum cross-correlation coefficients of the high-frequency event waveforms identified in the DAS recordings.
In addition to volcanic earthquakes, other natural source mechanisms may also be expected around Mount Meager, such as glacial stick-slip events, cryoseisms related to soil freezing, rockfalls, or fluid movement within the geothermal reservoir. However, each source mechanism would have a different $b$-value. The distributions and Figure $8 \mathrm{~b}$ are remarkably linear, indicating that the observed seismicity is dominated by a single source mechanism.

\subsubsection{Repeating Events}

To investigate the individual events in more detail, and to detect potentially repeating sources, we cross-correlated the waveforms in the stacked section for all events. The highest cross-correlation coefficients enter the cross-correlation matrix, visualized in Figure 9. The matrix reveals that numerous event pairs have high (absolute) correlation coefficients, often approaching \pm 1 .

To group similar events with high absolute correlation coefficients, we employed hierarchical clustering. For this, we convert the correlation matrix into a distance matrix by taking 1 minus its absolute value, which 

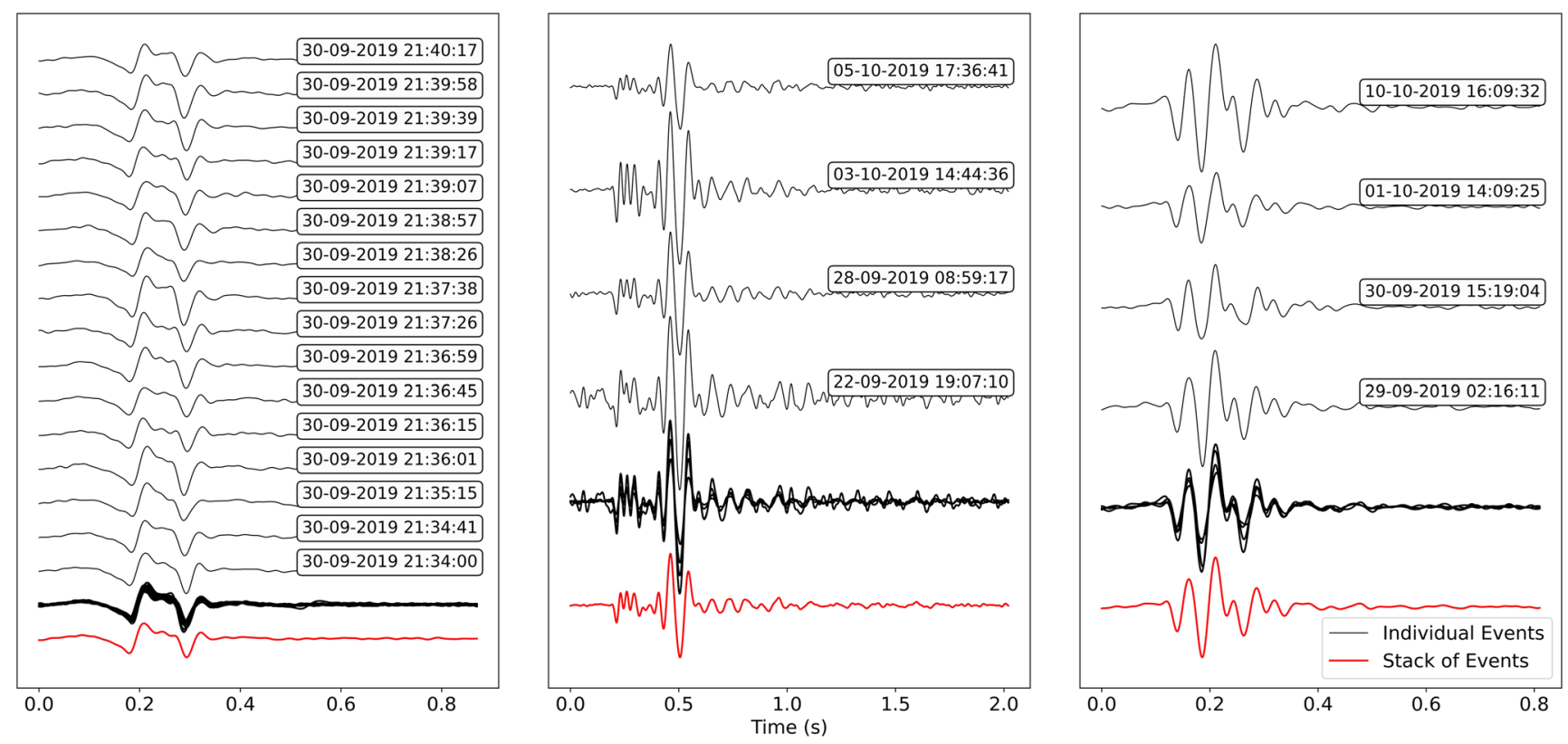

Figure 10. Examples of three different high-frequency event clusters were obtained from the hierarchical clustering algorithm. All clusters show a high similarity of events within them. The events are plotted vertically on top of each other in black, then they are all plotted overlapping onto each other below, and finally, they are stacked linearly to obtain the average waveform plotted at the bottom in red. The events in the left panel all occur within a few minutes of each other, while the other clusters show events that occurred on different days.

acts to also include events with high anti-correlations. The distance matrix serves as input to hierarchical clustering, where clusters are defined based on the distance between events (Virtanen et al., 2020). The algorithm starts with each event representing one cluster and iteratively merges clusters until only one large cluster remains. We choose a threshold of 0.05 to determine the distance that can exist between clusters, and to stop the merging of clusters at that level.

In total, the algorithm detects 37 clusters containing more than one event. Most significant among them are three clusters containing 6 events (within 2 weeks), 16 events (within $6 \mathrm{~min}$ ), and 111 events (within 27 days). The members of three representative event clusters are summarized in Figure 10.

\subsubsection{Beamforming}

While the largely unknown subsurface structure of Mount Meager, combined with its rough topography, currently prevent a precise event location, beamforming (Rost \& Thomas, 2002) can provide useful information about the dominant direction of wave propagation and a possible geographic clustering of sources. Beamforming rests on the assumptions of a distant source and a homogeneous half-space beneath the array. Since these assumptions are obviously not met in the complex environment around Mount Meager, it is important to keep in mind that the resulting slowness distributions must be interpreted as effective distributions. Nevertheless, when used as a comparative tool, we still expect similar events to yield similar apparent slowness and back-azimuths. In our specific case, we compute beam power as the normalized averaged cross-correlation coefficient of the time-shifted traces.

First, we developed a synthetic beamforming test to examine the reliability of a beamforming algorithm applied to DAS data. The tests, described in detail in Supporting Information S1 and S2, indicate that we indeed obtain reliable results under the assumption that we observe a single plane wave. Furthermore, the tests confirmed that recorded noise is coherent. Given high noise levels, the algorithm would converge to zero apparent slowness values. Another observation showed that the beamforming results can be improved by incorporating the SNR of each channel into the algorithm. We generally computed SNR values using noise windows directly before each event, to ensure comparable levels of background noise. We assume that the SNR implicitly contains information about the broadside sensitivity of the cable and the polarization of the event. Including only channels with a higher SNR does not alter the visual pattern of the recovered 


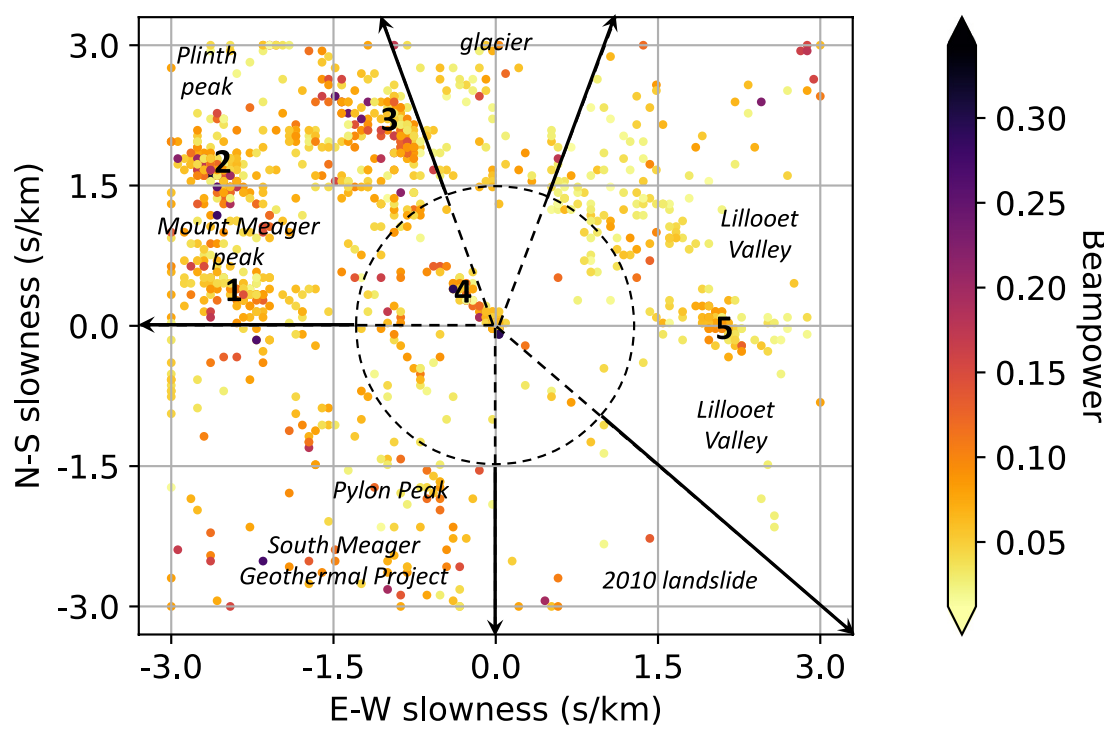

Figure 11. The beamforming results of the $\sim 1,000$ high-frequency $(5-45 \mathrm{~Hz})$ events with sufficiently high SNR. The location of each dot represents the optimal slowness for an event, and its color is the maximum beampower. The numbers 1-5 correspond to the different clusters that can be identified visually. Arrows and italic labels indicate the approximate locations of major topographic and geologic features.

slowness values, but it does increase the maximum beampower, that is, the overall coherence of the optimally time-shifted traces.

We applied the beamforming analysis to all detected events after an SNR check. The event catalog is based on the events detected in the stacked traces of the looped section (see Section 3), and not all the events are visible in the other channels. To decide in an automated fashion weather an event should be included in the beamforming, we computed the mean SNR of all DAS channels, normalized by the maximum SNR. We empirically found that an event was clearly visible throughout the DAS array when the resulting value exceeds 0.1 , and so it was included in the beamforming analysis. During the beamforming, we excluded individual channels when their SNR, normalized by the maximum SNR across the array, was below 0.5 . This procedure ensured a reasonable balance between the use of higher-quality traces and information loss due to smaller data volumes. Using these exclusion criteria reduced the number of events from the original $\sim 3,000$ to $\sim 1,000$.

As summarized in Figure 11, the beamforming results reveal five distinct slowness clusters, three of which are predominantly in the direction of the main topographic peaks of the volcanic complex. The few events that plot near the edges of the analyzed slowness space most likely represent airwaves, as they all occur early during the acquisition period, before a sufficiently thick snow cover provided additional acoustic insulation.

To identify events within the five visually discernible clusters in Figure 11, we employ the Density-Based Spatial Clustering of Applications with Noise (DBSCAN) algorithm (Ester et al., 1996; Schubert et al., 2017), which separates clusters characterized by a high density of events from areas with lower densities. Through trial and error, we define that a cluster forms when it can contain at least 40 events, and when the maximum Euclidean distance between events in one cluster is $4 \mathrm{~s} / \mathrm{m}$.

Based on the DBSCAN identification of events within the clusters, we can perform additional analyses, summarized in Supporting Information S1 and S2. Events within each of the clusters show a nearly exponential frequency-power distribution with only slightly different slopes and intercepts within the detectability range. Though the number of events per cluster is too small $(<200)$ to permit a rigorous statistical analysis, this result hints at similar source mechanisms. This is further supported by the cluster-wise waveform cross-correlation matrix, which indicates that waveforms within each cluster have average correlation coefficients above $\sim 0.5$, with individual correlation coefficients often approaching \pm 1 . 


\section{Discussion}

In the previous sections, we described the deployment logistics, data collection, and data analysis of a DAS experiment on a ridge of Mount Meager, an active, unstable, and glacier-clad volcano in western British Columbia, known for its significant geothermal potential.

Despite the challenging environment, it was possible to deploy $3 \mathrm{~km}$ of cable with 365 channels, with an array aperture of $\sim 500 \mathrm{~m}$. This required the dedicated work of three to five people over several days, as well as a helicopter to transport the equipment onto the otherwise inaccessible ridge.

The most critical aspects of the experiment were an autonomous power source that was sufficiently light to be transported, as well as the coupling of the cable. The latter required manual trenching over a distance of $3 \mathrm{~km}$, which was significant physical labor. Fortunately, the increasingly thick snow cover provided additional protection from wind and temperature fluctuations, which greatly improved data quality. A particularly beneficial component of the cable layout is the looped section, marked in green in Figure 2. It allowed us to estimate instrumental noise as a function of frequency, and it provided a high-quality stack that facilitated the detection of high-frequency events. Given the ease with which such a looped section can be deployed, it should probably become a standard component of future DAS installations.

Certainly, the most significant and unexpected scientific result is the sheer number and diversity of seismic events detected. The data quantity obtained with DAS was vital and could outweigh some of its limitations in rather unexplored and remote areas, such as Mount Meager. Thanks to the high number of events, we have been able to conduct basic statistical analyses, identify patterns in the data, and formulate educated hypotheses on the physical origin of the events.

The low-frequency events below $0.01 \mathrm{~Hz}$ initially show a diurnal pattern that is most likely caused by thermal expansion and contraction. The temperature fluctuations will have to be isolated from the strain data to enable comparisons with other long-period measurements, such as inSAR. Given available resources, future experiments should aim to include a Distributed Temperature Sensing (DTS) unit. Additionally, we would recommend to install a weather station and a camera at the site, to identify major environmental effects.

The intermediate-frequency events presented in Section 4.1 are most prominent between around 0.01 and $1 \mathrm{~Hz}$, and they may last several hours. The fact that they do not correlate with meteorological conditions and wave height data, suggests that these signals may be previously unknown volcanic tremor, possibly related to the movement of geothermal fluids. This is further supported by the observation that the character of these signals is unaffected by the shielding effect of the increasing snow cover during the experiment. Unfortunately, we could not constrain the direction of wave propagation with confidence due to the large wavelength compared to the array aperture. It would be interesting, however, to investigate the tremor signals in future experiments, possibly with a wider DAS array.

The high-frequency events (5-45 Hz) seem natural in origin, based on their nearly exponential frequency-power distribution. Possible origins of these events include volcanic activity, rockfalls on unstable slopes, glacial quakes, cryoseisms caused by freezing, and fluid movements related to the geothermal reservoir. Cross-correlation and beamforming analyses reveal distinct clusters, both in the similarity of the waveforms and their origin direction. The clusters labeled 1, 2, and 3 in Figure 11, are located in the direction of the main topographic peaks. Since we did not observe the order of 100 rockfalls per day during the deployment, and in the absence of obvious magmatic activity, we hypothesize that a geothermal origin is most likely. Cluster 4 in Figure 11 is located around 0 slowness, suggesting that events arrive directly from below the array. This leaves both geothermal activity and icequakes as possible sources. The origin of cluster 5 , located in the direction of the Lillooet Valley, is currently unclear. However, the frequency-power analysis shown in Supporting Information S1 and S2 at least indicates that the source mechanism may be similar to that of clusters 1-4. The freezing of water, especially during the colder periods, may cause a spatially more dispersed background of cryoseisms. However, due to their similar source process, they are practically indistinguishable from events caused, for instance, by fluid-induced cracking.

Most of the high-frequency events are not visible on the geophone array that has been installed around Mount Meager on a $10 \mathrm{~km}$ scale (Grasby \& Salas, 2020). Combined with the strong scattering that we 
observe, especially for the DAS channels located on the ridge (Figure 7), this suggests that the sources of the high-frequency events are located within a few kilometers of the array.

A significant improvement of the event location would require developments on many levels that are beyond the scope of this work. The aperture of the array would need to be expanded, especially to better constrain the directionality of the intermediate-frequency tremor. Furthermore, the geologic complexities would need to be accounted for. While modern numerical wave propagation tools permit modeling and inversion in media of almost arbitrary complexity (Afanasiev et al., 2019; Peter et al., 2011), the absence of precise knowledge of Mount Meager's subsurface structure still poses a very significant challenge.

Finally, we note that the observation of high-frequency events with waveforms that are almost exactly anti-correlated to waveforms from other events still awaits a plausible explanation, which is work in progress.

\section{Conclusions}

We have demonstrated the feasibility and potential of DAS in alpine, volcano-glacial environments, with moderate human and logistical effort.

The most significant scientific result is the unexpectedly high seismic activity of Mount Meager. This includes previously unknown volcanic tremor in the frequency range from around 0.01 to $1 \mathrm{~Hz}$ that can last for several hours. Though the source location cannot be constrained, we hypothesize that the tremor is related to the movement of fluids within the geothermal reservoir. At frequencies above $1 \mathrm{~Hz}$, we observe distinct transient events. We conservatively estimate their number to be around 3,000 during the 1-month acquisition period. Equally unknown before, these events have statistical properties that hint at a natural origin. The spatial density of the DAS array enables high-resolution beamforming, indicating that most events occur within three clusters in the direction of Mount Meager's main peak and Plinth peak. A waveform similarity analysis reveals that event sources often tend to repeat almost exactly, producing waveform correlation coefficients of nearly 1 . Most likely, these high-frequency events are also of geothermal origin.

In terms of the experimental setup, the most important lessons learned are the following: (a) A power source composed of a generator and a rechargeable battery pack can be sufficiently light to be transportable by helicopter, while providing autonomy for around one month of data acquisition. (b) As in other DAS experiments, coupling is essential. While trenching is physically challenging in volcanic and glacial environments, a snow cover provides useful additional shielding from meteorological effects. Hence, experiments should preferentially be set up just before the first snowfall. (c) A particularly beneficial aspect of the cable deployment is the looped section where numerous DAS channels are effectively co-located. It facilitates stacking and event identification, and also enables a straightforward estimation of frequency-dependent instrumental noise. Given the ease of producing a looped section, it should probably be a standard feature of future DAS deployments.

First-order improvements that may become part of future studies include a larger aperture of the DAS array (if permitted by the terrain), better cable-ground coupling that may enable measurements of long-term deformation, as well as more elaborate event location, for instance, on the basis of numerical wave propagation tools that account for rough topography and heterogeneous subsurface structure (if known).

\section{Data Availability Statement}

The data set is archived at Geoscience BC and is available upon request. In addition, a smaller subset of the data have been made available in a repository (Klaasen, 2021a). The created stack, a catalog of all high-frequency events, and the preprocessed data of all high-frequency events, decimated to $100 \mathrm{~Hz}$, are available. The Supporting Information S1 and S2 to this manuscript contains an example of the beamforming code on a single event, an animation that shows a few different events and their frequency content, and a video showing the deployment and recovery of the cables (Klaasen, 2021b). 
Acknowledgments

This study was supported by the Government of Canada's New Frontiers in Research Fund (NFRF), by Geoscience BC, by the Natural Resources Canada Emerging Renewable Power Program, and by the Geological Survey of Canada Geoscience for New Energy Program. The real-time Earthquake Risk Reduction for a Resilient Europe 'RISE' project has received funding from the European Union's Horizon 2020 research and innovation programme under grant agreement No 82111. The authors would like to thank the many members of the Mount Meager research team for the great research community they provide. The authors also thank C. Laing, J. France, and M. Karrenbach of OptaSense for tireless technical support. Marvin Jackson of Sundog Solar designed and supported the autonomous power source with a beyond-human effort. The authors thank Marco Accurso of No Limits Helicopters for carrying out many difficult flying tasks with sling loads at high elevation. The authors thank $\mathrm{H}$. Gilbert, G. Savard, J. Smale, J. Crompton, K. Biegel, P. Shahsavari, and S. Grasby for carrying out and supporting fieldwork. Sara Klaasen and Andreas Fichtner gratefully acknowledge the financial support of ETH Zürich, and the provision of the initial beamforming code by Daniel Bowden. Finally, S. Klaasen and A. Fichtner would like to thank S. Thrastarson and his family for turning their summer house into a scenic Icelandic quarantine location, where this manuscript received its final polishing. Open access funding provided by Eidgenossische Technische Hochschule Zurich.

\section{References}

Afanasiev, M. V., Boehm, C., van Driel, M., Krischer, L., Rietmann, M., May, D. A., et al. (2019). Modular and flexible spectral-element waveform modelling in two and three dimensions. Geophysical Journal International, 216. https://doi.org/10.1093/gji/ggy469

Beyreuther, M., Barsch, R., Krischer, L., Megies, T., Behr, Y., \& Wassermann, J. (2010). Obspy: A python toolbox for seismology. Seismological Research Letters, 81(3), 530-533. https://doi.org/10.1785/gssrl.81.3.530

Chouet, B. A. (1996). Long-period volcano seismicity: Its source and use in eruption forecasting. Nature, 380(6572), 309-316. https://doi. org $/ 10.1038 / 380309 \mathrm{a} 0$

Consortium Pacific Climate Impacts. (2013). BC station data. Retrieved from https://www.pacificclimate.org/data/bc-station-data

Corral, A., \& Gonzalez, A. (2019). Power-law distributions in geosciences revisited. Earth and Space Science, 6, 673-697.

Currenti, G., Jousset, P., Napoli, R., Krawczyk, C., \& Weber, M. (2021). On the comparison of strain measurements from fibre optics with dense seismometer array at Etna volcano (Italy). Solid Earth Discussions, 1-19.

De Martino, S., Falanga, M., Scarpa, R., \& Godano, C. (2005). Very-long-period volcanic tremor at Stromboli, Italy. Bulletin of the Seismological Society of America, 95(3), 1186-1192. https://doi.org/10.1785/0120040063

Esri. (2009). Esri imagery. Retrieved from https://www.arcgis.com/home/item.html?id=10df2279f9684e4a9f6a7f08febac2a9

Ester, M., Kriegel, H.-P., Sander, J., \& Xu, X. (1996). A density-based algorithm for discovering clusters in large spatial databases with noise. In Kdd (Vol. 96, pp. 226-231).

Grasby, S. E., \& Salas, C. (2020). Searching for Mount Meager's geothermal heart. Eos Transactions American Geophysical Union, 101. https://doi.org/10.1029/2020EO140214

Gutenberg, B. (1956). The energy of earthquakes. Quarterly Journal of the Geological Society, 112(1-4), 1-6. https://doi. org/10.1007/978-3-662-28668-5_1

Hartog, A. H. (2017). An introduction to distributed optical fibre sensors. CRC Press.

Henninges, J., Martuganova, E., Stiller, M., Norden, B., \& Krawczyk, C. M. (2021). Wireline distributed acoustic sensing allows 4.2 km deep vertical seismic profiling of the Rotliegend $150^{\circ} \mathrm{C}$ geothermal reservoir in the North German Basin. Solid Earth, 12(2), 521-537. https:// doi.org/10.5194/se-12-521-2021

Hickson, C., Russell, J., \& Stasiuk, M. (1999). Volcanology of the 2350 bp eruption of Mount Meager Volcanic Complex, British Columbia, Canada: Implications for hazards from eruptions in topographically complex terrain. Bulletin of Volcanology, 60(7), 489-507. https:// doi.org/10.1007/s004450050247

Jessop, A. M., Ghomshei, M. M., \& Drury, M. J. (1991). Geothermal energy in Canada. Geothermics, 20(5-6), 369-385. https://doi. org/10.1016/0375-6505(91)90027-s

Jousset, P., Reinsch, T., Ryberg, T., Blanck, H., Clarke, A., Aghayev, R., \& Krawczyk, C. M. (2018). Dynamic strain determination using fibre-optic cables allows imaging of seismological and structural features. Nature Communications, 9(1), 1-11. https://doi.org/10.1038/ s41467-018-04860-y

Kawakatsu, H., Kaneshima, S., Matsubayashi, H., Ohminato, T., Sudo, Y., Tsutsui, T., et al. (2000). Aso94: Aso seismic observation with broadband instruments. Journal of Volcanology and Geothermal Research, 101(1-2), 129-154. https://doi.org/10.1016/s0377-0273(00)00166-9

Klaasen, S. (2021a). Data repository for: Distributed acoustic sensing in volcano-glacial environments-Mount Meager, British Columbia. Zenodo. https://doi.org/10.5281/zenodo.4728303

Klaasen, S. (2021b). Supplementary information to: Distributed acoustic sensing in volcano-glacial environments-Mount Meager, British Columbia. Zenodo. https://doi.org/10.5281/zenodo.4723795

Konstantinou, K. I., \& Schlindwein, V. (2003). Nature, wavefield properties and source mechanism of volcanic tremor: A review. Journal of Volcanology and Geothermal Research, 119(1-4), 161-187. https://doi.org/10.1016/s0377-0273(02)00311-6

Krischer, L., Megies, T., Barsch, R., Beyreuther, M., Lecocq, T., Caudron, C., \& Wassermann, J. (2015). Obspy: A bridge for seismology into the scientific python ecosystem. Computational Science \& Discovery, 8(1), 014003. https://doi.org/10.1088/1749-4699/8/1/014003

Lindsey, N. J., Martin, E. R., Dreger, D. S., Freifeld, B., Cole, S., James, S. R., et al. (2017). Fiber-optic network observations of earthquake wavefields. Geophysical Research Letters, 44, 11792-11799. https://doi.org/10.1002/2017gl075722

Lindsey, N. J., Rademacher, H., \& Ajo-Franklin, J. B. (2020). On the broadband instrument response of fiber-optic das arrays. Journal of Geophysical Research: Solid Earth, 125(2), e2019JB018145. https://doi.org/10.1029/2019jb018145

Martin, E. R., Castillo, C. M., Cole, S., Sawasdee, P. S., Yuan, S., Clapp, R., et al. (2017). Seismic monitoring leveraging existing telecom infrastructure at the SDASA: Active, passive, and ambient-noise analysis. The Leading Edge, 36, 1025-1031. https://doi.org/10.1190/ tle36121025.1

Mateeva, A., Lopez, J., Potters, H., Mestayer, J., Cox, B., Kiyashchenko, D., et al. (2014). Distributed acoustic sensing for reservoir monitoring with vertical seismic profiling. Geophysical Prospecting, 62, 679-692. https://doi.org/10.1111/1365-2478.12116

McNutt, S. R., \& Roman, D. C. (2015). Volcanic seismicity. In The encyclopedia of volcanoes (pp. 1011-1034). Elsevier. https://doi. org/10.1016/b978-0-12-385938-9.00059-6

Michol, K., Russell, J., \& Andrews, G. (2008). Welded block and ash flow deposits from Mount Meager, British Columbia, Canada. Journal of Volcanology and Geothermal Research, 169(3-4), 121-144. https://doi.org/10.1016/j.jvolgeores.2007.08.010

Paitz, P., Edme, P., Gräff, D., Walter, F., Doetsch, J., Chalari, A., et al. (2020). Empirical investigations of the instrument response for distributed acoustic sensing (DAS) across 17 octaves. Bulletin of the Seismological Society of America, 111(1), 1-10.

Peter, D., Komatitsch, D., Luo, Y., Martin, R., Le Goff, N., Casarotti, E., et al. (2011). Forward and adjoint simulations of seismic wave propagation on fully unstructured hexahedral meshes. Geophysical Journal International, 186, 721-739. https://doi. org/10.1111/j.1365-246x.2011.05044.x

Read, P. B. (1990). Mount Meager Complex, Garibaldi Belt, Southwestern British Columbia, Canada. Geoscience Series, 17(3).

Roberti, G., Ward, B., de Vries, B., van Wyk, B., Falorni, G., Menounos, B., et al. (2018). Landslides and glacier retreat at Mt. Meager volcano: Hazard and risk challenges. GeoHazards, 7.

Roberti, G., Ward, B., de Vries, B., van Wyk, B., Friele, P., Perotti, L., \& Giardino, M. (2018). Precursory slope distress prior to the 2010 Mount Meager Landslide, British Columbia. Landslides, 15(4), 637-647. https://doi.org/10.1007/s10346-017-0901-0

Roberts, N. S., Bell, A. F., \& Main, I. G. (2015). Are volcanic seismic $b$-values high, and if so when? Journal of Volcanology and Geothermal Research, 308, 127-141. https://doi.org/10.1016/j.jvolgeores.2015.10.021

Rost, S., \& Thomas, C. (2002). Array seismology: Methods and applications. Reviews of Geophysics, 40(3), 2-1-2-27. https://doi. org/10.1029/2000rg000100

Schlindwein, V., Wassermann, J., \& Scherbaum, F. (1995). Spectral analysis of harmonic tremor signals at Mt. Semeru Volcano, Indonesia. Geophysical Research Letters, 22(13), 1685-1688. https://doi.org/10.1029/95gl01433 
Schubert, E., Sander, J., Ester, M., Kriegel, H. P., \& Xu, X. (2017). DBSCAN revisited, revisited: Why and how you should (still) use DBSCAN. ACM Transactions on Database Systems, 42(3), 1-21. https://doi.org/10.1145/3068335

Virtanen, P., Gommers, R., Oliphant, T. E., Haberland, M., Reddy, T., Cournapeau, D., et al. (2020). SciPy 1.0 ContributorsSciPy 1.0: Fundamental algorithms for scientific computing in Python. Nature Methods, 17, 261-272. https://doi.org/10.1038/s41592-019-0686-2

Walter, F., Gräff, D., Lindner, F., Paitz, P., Köpfli, M., Chmiel, M., \& Fichtner, A. (2020). Distributed acoustic sensing of microseismic sources and wave propagation in glaciated terrain. Nature Communications, 11(1), 1-10. https://doi.org/10.1038/s41467-020-15824-6

Wassermann, J. (2012). Volcano seismology. In New manual of seismological observatory practice 2 (pp. 1-77). Deutsches GeoForschungsZentrum GFZ.

Withers, M., Aster, R., Young, C., Beiriger, J., Harris, M., Moore, S., \& Trujillo, J. (1998). A comparison of select trigger algorithms for automated global seismic phase and event detection. Bulletin of the Seismological Society of America, 88(1), 95-106. https://doi.org/10.1785/ bssa0880010095

Zhan, Z. (2020). Distributed acoustic sensing turns fiber-optic cables into sensitive seismic antennas. Seismological Research Letters, 91(1), 1-15. https://doi.org/10.1785/0220190112 